\title{
Comparison of Different Ground-Based NDVI Measurement Methodologies to Evaluate Crop Biophysical Properties
}

\author{
Rossana Monica Ferrara*, Costanza Fiorentino, Nicola Martinelli, \\ Pasquale Garofalo, Gianfranco Rana \\ CRA - Unità di Ricerca per i Sistemi Colturali degli Ambienti caldo-aridi \\ Via Celso Ulpiani 5, 70125 Bari, Italy
}

Received: 7 September 2009. Accepted: 26 November 2009.

\begin{abstract}
The usage of vegetation indices such as the Normalized Difference Vegetation Index (NDVI) calculated by means of remote sensing data is widely spread for describing vegetation status on large space scale. However, a big limitation of these indices is their inadequate time resolution for agricultural purposes. This limitation could be overcome by the ground-based vegetation indices that could provide an interesting tool for integrating satellite-based value. In this work, three techniques to calculate the ground-NDVI have been evaluated for sugar beet cultivated in South Italy in all its phenological phases: the NDVI 1 based on hand made reflectance measurements, the $\mathrm{NDVI}_{2}$ calculated on automatically reflectance measurements and the broadband $\mathrm{NDVI}_{\mathrm{b}}$ based on Photosynthetically Ac-

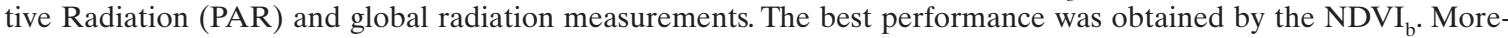
over, crop-microclimate-NDVI relations were investigated. In particular, the relationship between NDVI and the Leaf Area Index (LAI) was found logarithmic with a saturation of NDVI at LAI around $1.5 \mathrm{~m}^{2} \mathrm{~m}^{-2}$. A clear relation was found between NDVI and crop coefficient $\mathrm{K}_{\mathrm{c}}$ experimentally determined by the ratio between actual and reference measured or modelled evapotranspirations, while the relation between NDVI and crop actual evapotranspiration was very weak and not usable for practical purposes. Lastly, no relationship between the microclimate and the NDVI was found.
\end{abstract}

Key-words: actual evapotranspiration, broadband NDVI, eddy covariance, sugar beet.

\section{Introduction}

The Normalized Difference Vegetation Index (NDVI) is the most commonly used satellite index to evaluate the land use because it is closely correlated to: (i) the fraction of soil covered by crop, the Leaf Area Index (LAI) and land classification (Brown et al., 1993; Townshend et al., 1994; Duchemin et al., 2006 among many others), (ii) the biophysical properties and the net primary production (Prince, 1991; Goward and Huemmerich, 1992; Sellers et al., 1994) and, as recently demonstrated, (iii) the crop water status and the crop water requirements (D'Urso and Calera Belmonte, 2006; Garatuza-Payan and Watts, 2005; Samani et al., 2006; Bajwa and Voies, 2006; Duchemin et al., 2006). On the other hands, the most used method to calculate the crop water requirements (i.e. actual evapotranspiration, ET) is the so called crop coefficient $\left(\mathrm{K}_{\mathrm{c}}\right)$ approach (Allen et al., 1998); $\mathrm{K}_{\mathrm{c}}$ depends on the dynamics of canopies (cover fraction, LAI, water status and greenness) like the path of NDVI along a growth season. Therefore, relationships between NDVI and $\mathrm{K}_{\mathrm{c}}$ are supposed to be useful for irrigation operational purposes (Choudhury et al., 1994; Ray and Dadhwal, 2001; Bandyopadhyay and Mallick, 2003; D'Urso and Calera Belmonte, 2006). Crop coefficients calculated using satellite collected NDVI 
time series, coupled to other observations for characterizing the timing, dynamics, and distribution of phytophenological events (Azzali and Menenti, 1999) are been used to manage irrigation water. Good results are obtained, for example, by the EU project DEMETER in European countries (Osann Jochum et al., 2006) when the crop water requirement is calculated on the basis of the crop coefficient approach using satellite-based NDVI, coupled with meteorological data acquired at ground for establishing the irrigation scheduling (D'Urso and Calera Belmonte, 2006; Vuolo et al., 2006; Café et al., 2006).

NDVI time series are commonly obtained by processing the data collected by advanced high resolution satellite remote sensors. Nevertheless, satellite data at high temporal resolution are often unavailable because of the satellite time revisit, the presence of cloud cover or the high costs of images.

Then, NDVI time series can loose their temporal resolution and dynamic, making sometimes difficult their use for practical purposes in agriculture. In order to have high temporal resolution series of NDVI to a daily time-step, the useful operational scale, ground calculated indices should be used, interpolating them from a function fit to a smoothed NDVI time series (Huemmerich et al., 1999; Wang et al., 2004). However, to our knowledge, few studies have been reported in international scientific literature on the accuracy of ground-based NDVI time series, seemingly due to the lack of appropriate experimental data (Wiegand and Richardson, 1990; Wang et al., 2004; Gonzàlez-Dugo and Mateos, 2006).

The objective of this work is to evaluate the performance of NDVI measured on ground by three different methods, for determining the LAI, the crop actual ET and the $\mathrm{K}_{\mathrm{c}}$ of sugar beet crop, grown in a site of southern Italy, submitted to usual agronomical practices to obtain the best yield. Furthermore, relationships between the crop microclimate and these NDVI's were also searched for. The aims of this paper are (i) to investigate about the possibility to integrate satellite-based NDVI time series with ground-based series for irrigation command area management and (ii) to improve the understanding of the crop-microclimate-NDVI relations for open field crops.

\section{Materials and methods}

\subsection{The site and the crop}

This study was carried out at a site of southern Italy (Capitanata plain) in 2006, 2007 and 2008 during three experimental field campaigns planned for the national research project AQUATER. The data here presented were acquired in two private farms ("Forte" during 2006 and "De Lucretis" during 2007 and 2008), on a very large field (more than 5 hectares) of autumnal sugar beet (Beta vulgaris L.). The irrigation water was supplied by the "Consorzio per la Bonifica della Capitanata (Foggia)", by aspersion method, following the local crop management aimed at maximising yield. The climate is "accentuated thermomediterranean" (Unesco-FAO classification), with temperatures below $0{ }^{\circ} \mathrm{C}$ in the winter and above $40{ }^{\circ} \mathrm{C}$ in the summer. Annual rainfall (mean $550 \mathrm{~mm}$ ) is mostly concentrated during the winter months and reference evapotranspiration $\left(\mathrm{ET}_{0}\right)$ exceeds $5 \mathrm{~mm} \mathrm{day}^{-1}$ in summer (Fig. 1). LAI was measured at random georeferenced points within each field by using a Li-Cor LAI2000 (Li-Cor, USA) that measures the blue light $(320-490 \mathrm{~nm})$

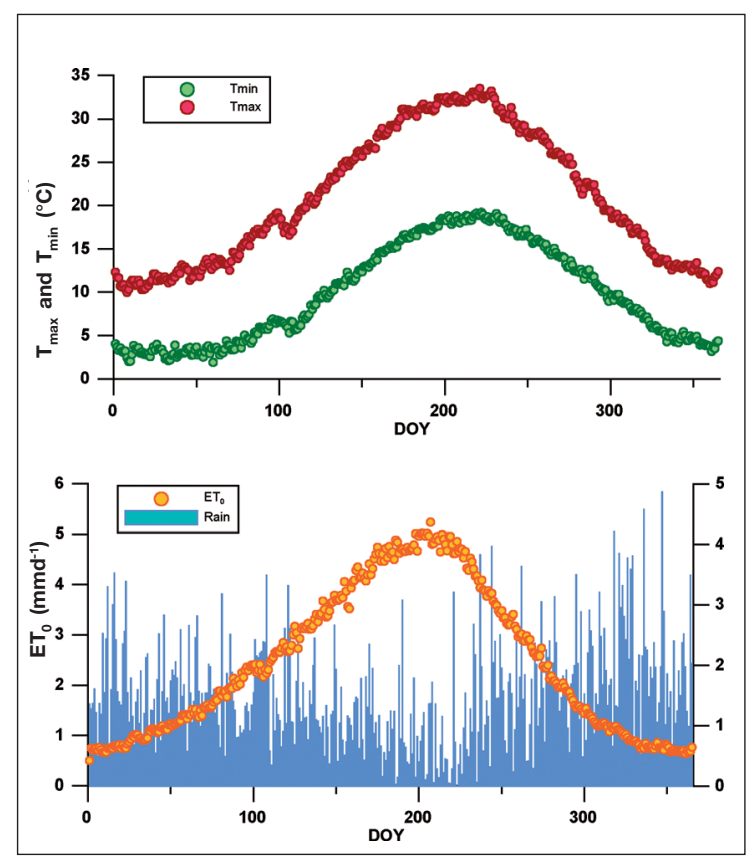

Figure 1. Daily fifty years average values of rain, reference evapotranspiration $\left(\mathrm{ET}_{0}\right)$, maximum $\left(\mathrm{T}_{\max }\right)$ and minimum $\left(\mathrm{T}_{\mathrm{min}}\right)$ air temperature in function of DOY (Day Of the Year). 
transmitted through the canopy in 5 concentric cones (with $148^{\circ}$ field of view). Randomization procedure was done splitting each field into three plots: for each plot a point into the middle was georeferenced. Starting from this point, moving to the left and right, 12 measurements of LAI for each georeferenced point were carried out at a distance among them of about 10 meters and 30 meters in length and width respectively (Fig. 2). Six values of LAI for each field were obtained by this randomization procedure.

\subsection{The NDVI indices, the evapotranspiration and the microclimate}

The chlorophyll strongly absorbs the red (R) wavelength of the electromagnetic spectrum for use in photosynthesis, on the other hand, leaf cells have also evolved to scatter solar radiation in the near-infrared (NIR) spectrum region. The NDVI is calculated, using these properties of vegetation, as follow (Rouse et al., 1974):

$$
N D V I=\frac{\rho_{N I R}-\rho_{R}}{\rho_{N I R}+\rho_{R}}
$$

where $\rho$ can be digital counts, at-satellite radiance, top of the atmosphere apparent reflectances, land-leaving surface radiance, surface reflectances or hemispherical spectral albedos (Huete et al., 1999). In this work, the NDVI has been estimated by applying three different approaches.

The first one $\left(\mathrm{NDVI}_{1}\right)$ is calculated by the previous Eq. (1) using the hand-held MSR5 multispectral radiometer (Cropscan INC., USA). This instrument measures both incoming and reflected radiation over five optical bands including the first five ones of Thematic Mapper sensors onboard the successive Landsat missions. Two of these bands are centred on red (0.63-0.69 $\mu \mathrm{m})$ and near-infrared $(0.76-0.99 \mu \mathrm{m})$ wavelengths. When this sensor was used, measurements were made along two transects (NorthSouth and East-West), on 4 points every $10 \mathrm{~m}$ around the centre of the plot, on weekly basis, at solar noon. For every point, 8 repetitions have been carried out. The second NDVI $\left(\mathrm{NDVI}_{2}\right)$ is calculated using always the Eq. (1) by measuring the reflectances by means of the automatic multispectral radiometer SKR1850 (Skye Instruments Ltd, UK). It has four channel light sensors for measuring incoming and outcoming radiation. For

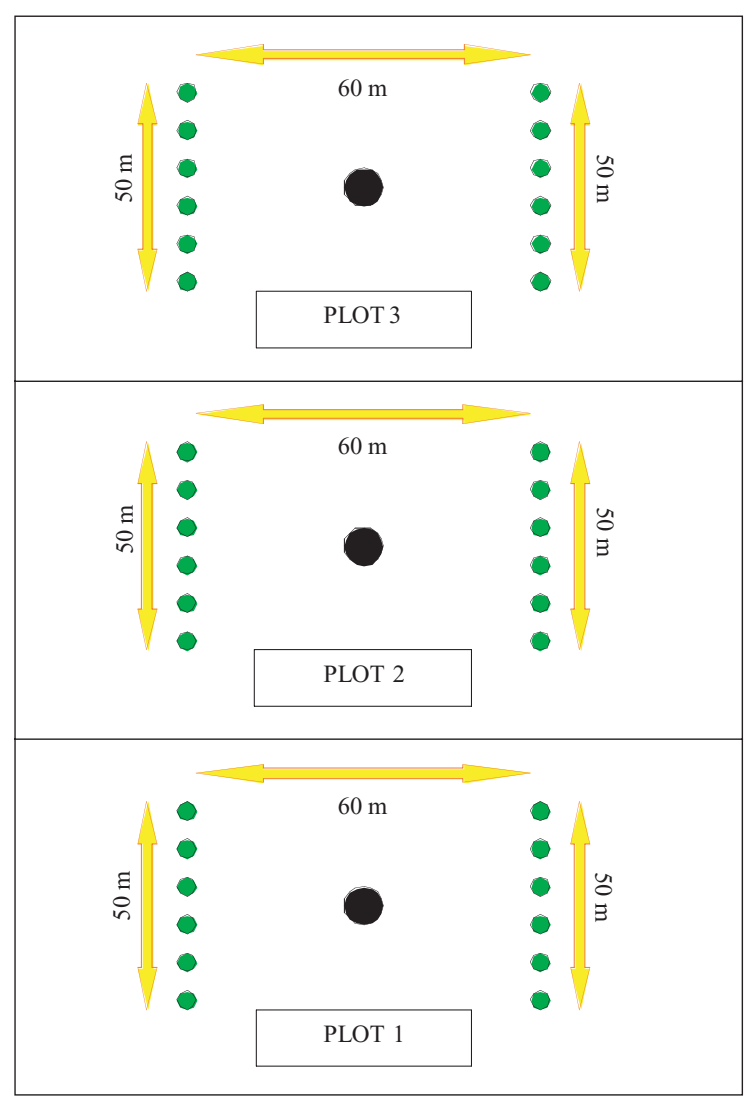

Figure 2. Schematic representation of randomization procedure for LAI measurements in the field.

the calculation of $\mathrm{NDVI}_{2}$ the optical bands were centred on $0.661 \mu \mathrm{m}$ and $0.830 \mu \mathrm{m}$ wavelengths for red and near-infrared respectively. The values of these radiations have been acquired continuously by a datalogger CR10X (Campbell Sci, UK), with $10 \mathrm{~s}$ intervals and averaging time of 1 hour. It was installed $1.5 \mathrm{~m}$ above the crop.

Huemmerich et al. (1999) replaced the red domain with Photosynthetically Active Radiation (PAR) and the near-infrared with an optical infrared domain in order to use the upward and downward PAR and global radiation sensors measurements. Thus, another spectral index can be used, it is the broadband NDVI (NDVI $)$ calculated as:

$$
N D V I_{b}=\frac{\rho_{\text {OIR }}-\rho_{A R}}{\rho_{\text {OIR }}+\rho_{A R}}
$$

where $\rho_{\text {PAR }}$ is PAR reflectance, i.e. the ratio of reflected and incoming PAR measured by downward and upward quantum sensors respectively 


$$
\rho_{P A R}=\frac{P A R_{r}}{P A R_{i}}
$$

and $\rho_{\text {OIR }}$ is the reflectance of optical infrared radiance (irradiance value between the difference of global radiation and PAR), calculated as

$$
\rho_{\text {OIR }}=\frac{R_{g r}-P A R_{r}}{R_{g i}-P A R_{i}}
$$

where $\mathrm{R}_{\mathrm{gi}}$ and $\mathrm{R}_{\mathrm{gr}}$ are incoming and reflected global radiation respectively. In this case PAR and $R_{g}$, both reflected and incident, were measured continuously with sensors SKP210 and SKS1100 (Skye Ins., UK) respectively, by a datalogger CR10X (Campbell Sci., UK).

The measurements of reflectance used to calculate $\mathrm{NDVI}_{2}$ and $\mathrm{NDVI}_{\mathrm{b}}$ were carried out at the centre of each plot where the meteorological and micrometeorological variables were monitored (Fig. 3).

The actual evapotranspiration of the crop was measured by the eddy covariance method

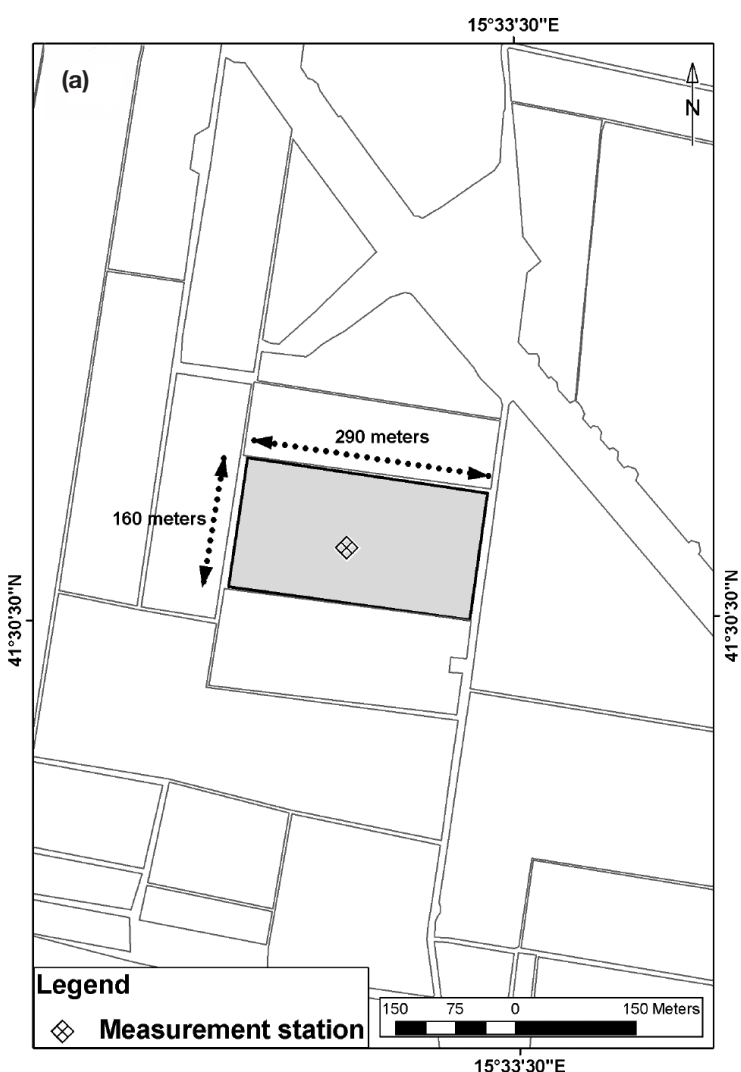

(EC) (Kaimal and Finnigan, 1994). A three-dimensional sonic anemometer (USA-1, Metek, Germany) was used coupled with an open-path sensor for the fast acquisition of water vapor concentration (LI-7500, Li-Cor, USA). The sensors were connected to an industrial computer and acquired by software (MeteoFlux, Servizi Territorio S.r.l., Cinisello B. (Mi), Italy).

Since the objective of this study was to evaluate the performance of NDVI indices in any climate and crop conditions along the whole growing season, in order to evaluate the most complete time series, in case of failure of the EC technique, the model shown in Katerji and Rana (2008) was used for filling the gaps. In this case ET is equal to

$$
E T=\frac{1}{\lambda} \frac{\Delta A+\rho c_{p} D / r_{a}}{\Delta+\gamma\left(1+r_{c} / r_{a}\right)}
$$

where $A=R_{n}-G$ is the available energy $\left(\mathrm{W} \mathrm{m}^{-2}\right)$, $\rho$ is the air density $\left(\mathrm{kg} \mathrm{m}^{-3}\right), \Delta$ is the slope of the saturation pressure deficit versus tempera-

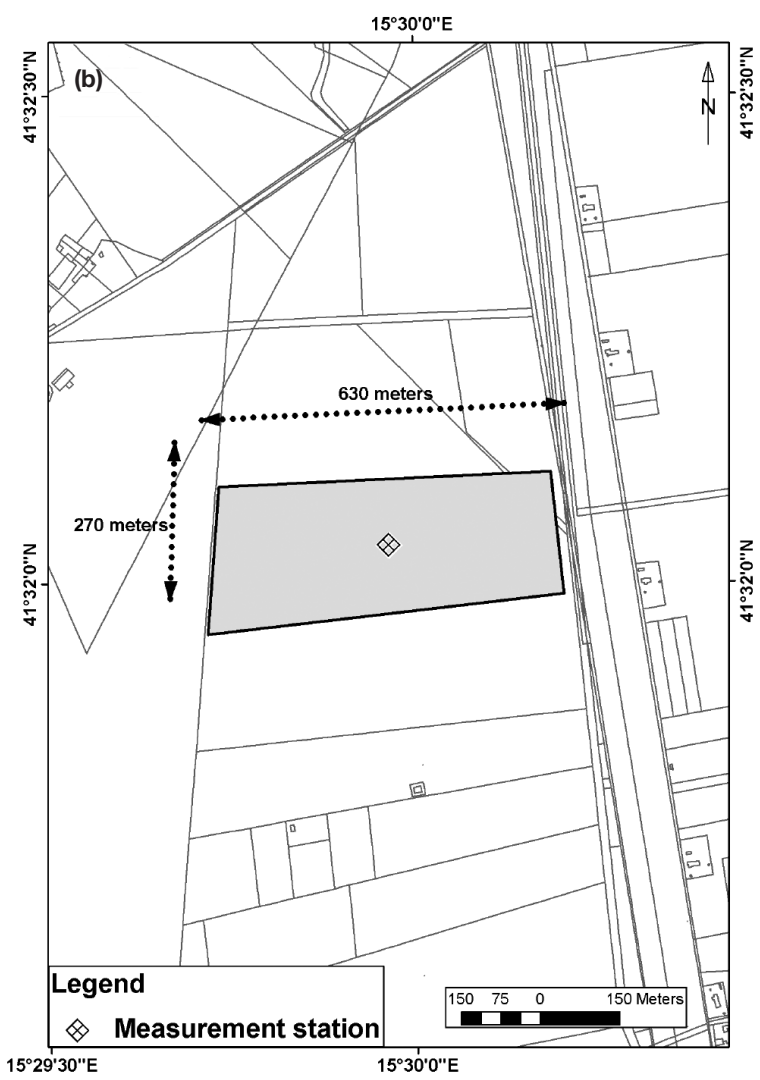

Figure 3. Maps of the experimental fields in the two farms: (a) Forte and (b) De Lucretis with location of the experimental devices employed for meteorological, micrometeorological and radiometric $\left(\mathrm{NDVI}_{2}\right.$ and $\left.\mathrm{NDVI}_{\mathrm{b}}\right)$ variables. 
ture function $\left(\mathrm{kPa} \mathrm{C}^{-1}\right), \gamma$ is the psychrometric constant $\left(\mathrm{kPa} \mathrm{C}^{-1}\right), \mathrm{c}_{\mathrm{p}}$ is the specific heat of moist air $\left(\mathrm{J} \mathrm{kg}^{-1} \mathrm{C}^{-1}\right), \mathrm{D}$ is the vapor pressure deficit of the air $(\mathrm{kPa}), \mathrm{r}_{\mathrm{c}}$ is the bulk canopy resistance $\left(\mathrm{s} \mathrm{m}^{-1}\right)$ and $\mathrm{r}_{\mathrm{a}}$ is the aerodynamic resistance $\left(\mathrm{s} \mathrm{m}^{-1}\right), \lambda$ is the latent heat of evaporation $\left(\mathrm{J} \mathrm{kg}^{-1}\right)$. The aerodynamic resistance $r_{\mathrm{a}}$ was calculated between the top of the crop and a reference point $\mathrm{z}$ sited in the boundary layer above the canopy, following Perrier (1975a; 1975b), as a function of wind speed $\mathrm{u}\left(\mathrm{m} \mathrm{s}^{-1}\right)$ measured 2 $\mathrm{m}$ above the crop. All the variables were measured directly above the crop, by commercial sensors after accurate calibration in laboratory.

For calculating ET in the Eq. (5), the canopy resistance $r_{c}$ has to be previously determined. In the present work, the hourly variation of $r_{c}$ is simulated starting from a relationship taking into account the associated effects of solar radiation, air vapour pressure deficit and wind speed. Katerji and Perrier (1983) proposed to simulate the resistance $r_{c}$ by the following relation:

$$
\frac{r_{c}}{r_{a}}=a \frac{r^{*}}{r_{a}}+b
$$

where $\mathrm{a}$ and $\mathrm{b}$ are empirical calibration coefficients which requires experimental determination (Katerji and Rana, 2008). For sugar beet the coefficient "a" and "b" were 0.45 and 4.49 respectively (Ferrara et al., 2008). $\mathrm{r}^{*}\left(\mathrm{~s} \mathrm{~m}^{-1}\right)$ is given by:

$$
r^{*}=\frac{\Delta+\gamma}{\Delta \gamma} \frac{\rho c_{p} D}{A}
$$

This resistance r* can be considered as a "climatic" resistance, because it depends only on weather variables. This model has been used to calculate ET for different species (alfalfa, rice, grass, lettuce, sweet sorghum, sunflower, grain sorghum, soybean, clementine orchard, sloping grassland) as reported by Katerji and Rana (2006). The daily values of ET were calculated, considering in this direct method (index "d") the sum of hourly values in the time interval between 8 a.m. and 6 p.m.:

$$
E T_{d}=\sum_{h=8}^{18} E T
$$

The crop coefficient $\mathrm{K}_{\mathrm{c}}$ for sugar beet was calculated as:

$$
K_{c}=\frac{E T_{d}}{E T_{0}}
$$

In this relation the daily reference evapotranspiration $\mathrm{ET}_{0}$ was calculated by cumulating the hourly values of ET estimated by the model (5), with the coefficients $a=0.16$ and $b=0$ corresponding to those of a well water short grass (Rana et al., 1994; Katerji and Rana, 2006). The $\mathrm{ET}_{0}$ was not estimated by the Penman-Monteith given in FAO56 (Allen et al., 1998), since Katerji and Rana (2006) demonstrated that in Apulia sites this equation does not work correctly. The same kind of sensors used for measuring agrometeorological variables on the sugar beet were also used to measure the meteorological variables for calculating $\mathrm{ET}_{0}$, in this case the sensors were placed above a reference grass in an agrometeorological station few kilometers far from the experimental fields.

In all cases, for the micrometeorological measurement of variables and fluxes the fetch in all the directions was large enough for being well below the adjusted internal crop boundary layer. The measurements were carried out from 14 April to 15 May 2006, from 12 April to 16 June 2007, from 25 January to 10 April 2008, therefore all the phenological phases of sugar beet were covered from sowing to harvest.

\section{Results and discussion}

The EC technique failed for about $33 \%$ of the measurements due to power supply breaks and equipment failure, so, to cover this period the ET was calculated by the model above described. The good agreement between the modelled and measured ET is shown in Figure 4 where a comparison at daily time scale is made. Moreover, details about the performance of the presented model are given in Ferrara et al. (2008).

In order to compare the three considered indices in the same experimental conditions, the values of $\mathrm{NDVI}_{1}, \mathrm{NDVI}_{2}$ and $\mathrm{NDVI}_{\mathrm{b}}$ measured at noon (12:00 solar local time) in selected clear days are shown in Table 1, together with the standard deviation (SD). From this table it is clear that the mean values of the three indices are very close in each considered day, but the standard deviations are very different. Actually, the $\mathrm{SD}$ for $\mathrm{NDVI}_{1}$ is mainly due to the spatial variability of the measurements along the tran- 


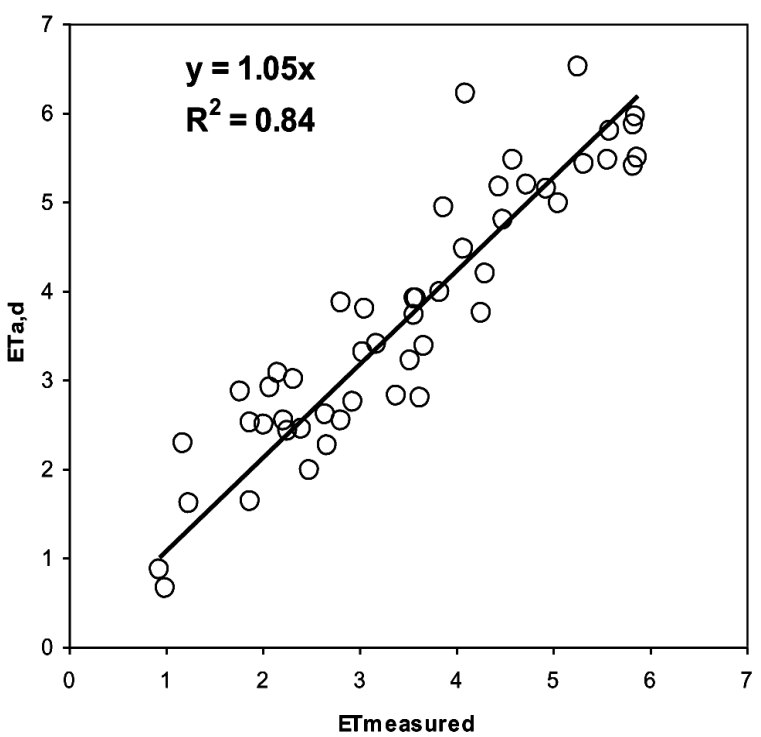

Figure 4. Comparison between daily values of actual ET modelled by the presented model and ET directly measured in the field by eddy covariance or aerodynamic method on sugar beet during 2007, when LAI $\geq 2$ (data reported in Ferrara et al., 2008).

sects, while the SD for $\mathrm{NDVI}_{2}$ and $\mathrm{NDVI}_{\mathrm{b}}$ are the ones recorded by the datalogger and due to the time variability of the measurements carried out by fixed above crop sensors for one hour every 10 seconds. Anyway, for these two last indeces in this given climatic condition (clear days), the $\mathrm{NDVI}_{\mathrm{b}}$ showed the lowest SD (ranging from 0.01 to 0.03 ) while the $\mathrm{NDVI}_{2}$ showed the worst SD $(0.01 \div 0.12)$. The problem of the temporal variability of NDVI measured at ground seems to be important either for the NDVI calculated from canopy reflectance $\left(\mathrm{NDVI}_{1}\right.$ and $\mathrm{NDVI}_{2}$, Duchemin et al., 2006) or for the broadband $\mathrm{NDVI}_{\mathrm{b}}$ (Wang et al., 2004). Nevertheless, the variability of NDVI is strongly dependent on the climatic conditions, seemingly due to the cloud cover of the sky. In fact, the $\mathrm{NDVI}_{2}$ and $\mathrm{NDVI}_{\mathrm{b}}$ assume highly variable values during cloud cover days and, above all, for rainy days (Table 2). Actually, on the other hands, the path of NDVI along the day shows a daily trend both for clear, partly cloudy and cloudy days (Wang et al., 2004), as shown in Figure 5 for $\mathrm{NDVI}_{2}$ and $\mathrm{NDVI}_{\mathrm{b}}$, the indices automatically acquired in continuous. This trend could be either linked to sun angle effects or leaf angle modification due to water stress; however, no data are available to investigate these two hypothetic causes. However, the variation of both indices around noon $(1100 \div 1400)$ is small on clear days.

Since the LAI of sugar beet was measured at weekly/biweekly time scale, in order to obtain a clear relationship between LAI and NDVI we compared the observations of all the three years together, selecting the values of available NDVIs at noon for the days with measurements of LAI. The NDVI shows a logarithmic response to LAI (Fig. 6), in close agreement with results obtained using satellite-based NDVI by Baret et al. (1989), Richardson et al. (1992) and more recently by Duchemin et al. (2006). The comparison in Figure 6 clearly

Table 1. Values of $\mathrm{NDVI}_{1}, \mathrm{NDVI}_{2}$ and $\mathrm{NDVI}_{\mathrm{b}}$ measured at noon (solar local time) during clear days. SD is standard deviation.

\begin{tabular}{lcccccc}
\hline Day & NDVI $_{1}$ & $\mathrm{SD}_{1}$ & $\mathrm{NDVI}_{2}$ & $\mathrm{SD}_{2}$ & $\mathrm{NDVI}_{\mathrm{b}}$ & $\mathrm{SD}_{\mathrm{b}}$ \\
\hline $20 / 01 / 2007$ & 0.01 & 0.16 & 0.10 & 0.09 & 0.08 & 0.01 \\
$25 / 01 / 2007$ & 0.32 & 0.22 & 0.35 & 0.12 & 0.28 & 0.01 \\
$13 / 03 / 2007$ & 0.50 & 0.23 & 0.55 & 0.09 & 0.44 & 0.01 \\
$12 / 04 / 2007$ & 0.80 & 0.21 & 0.77 & 0.02 & 0.65 & 0.03 \\
$21 / 05 / 2007$ & 0.80 & 0.18 & 0.80 & 0.01 & 0.82 & 0.01 \\
$21 / 06 / 2007$ & 0.85 & 0.22 & 0.85 & 0.04 & 0.80 & 0.01 \\
\hline
\end{tabular}

Table 2. Variability of Standard Deviation for $\mathrm{NDVI}_{2}$ and $\mathrm{NDVI}_{\mathrm{b}}$ for the years 2007 and 2008 by distinguishing among clear, cloudy and rainy days.

\begin{tabular}{lcccc}
\hline & \multicolumn{2}{c}{2007 Min - Max } & \multicolumn{2}{c}{2008 Min - Max } \\
\hline Clear days & $\mathrm{NDVI}_{2}$ & $\mathrm{NDVI}_{\mathrm{b}}$ & $\mathrm{NDVI}_{2}$ & $\mathrm{NDVI}_{\mathrm{b}}$ \\
Cloudy days & $0.01-0.12$ & $0.01-0.06$ & $0.11-0.17$ & $0.01-0.04$ \\
Rainy days & $0.09-0.40$ & $0.01-0.05$ & $0.18-0.45$ & $0.01-0.05$ \\
\hline
\end{tabular}



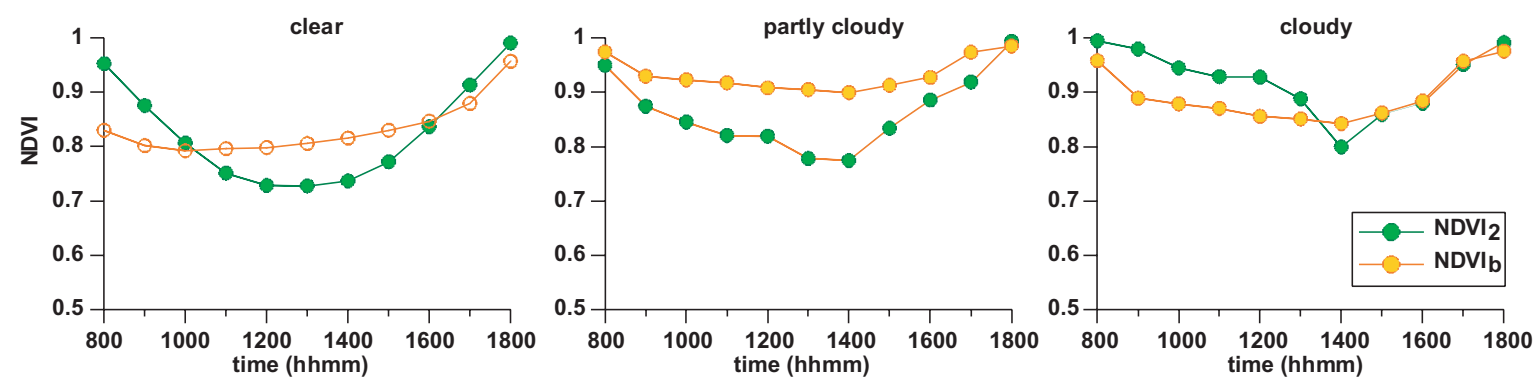

Figure 5. Daily variation of $\mathrm{NDVI}_{2}$ and $\mathrm{NDVI}_{\mathrm{b}}$ during clear (DOY 63), partly cloudy (DOY 69) and cloudy (DOY 67) weather condition during 2008. DOY is Day Of the Year.

shows the NDVI saturation at LAI values greater than 1.5. These results are in agreement with those found by Gonzàles-Dugo and Mateos (2006) using field radiometry on sugar beet grown in Spain. In fact, these authors found similar relationship between LAI and NDVI, and NDVI saturation at LAI values of $2 \mathrm{~m}^{2} \mathrm{~m}^{-2}$ for sugar beet and $1.5 \mathrm{~m}^{2} \mathrm{~m}^{-2}$ for cotton.

Considering the lower variability of the broadband NDVI with respect to $\mathrm{NDVI}_{2}$, to investigate the relationships between NDVI and evapotranspiration, the $\mathrm{NDVI}_{\mathrm{b}}$ has been used. In particular, the seasonal courses of daily actual evapotranspiration and the $\mathrm{NDVI}_{b}$ measured at noon are plotted together in Figure 7. The measurements of 2007 and 2008 are put together in order to cover the whole growing cycle with all the phenological phases. The ET values ranged between $0.5 \mathrm{~mm} / \mathrm{d}$, when the crop is in early stage or the daily solar radiation is very low, to $6-7 \mathrm{~mm} / \mathrm{d}$ when the crop is fully devel- oped. The NDVI ${ }_{b}$ seems to follow the path of daily ET; however, a regression between these two variables does not show a significant relationship $\left(\mathrm{r}^{2}<0.3\right)$, even if only the very clear days were selected. During 2008 a close sequence of violent storms in the period $20 \mathrm{Feb}-$ ruary - 10 March (Day Of the Year 51-70) strongly damaged the sugar beet, causing a decreasing of green leaf area. This decreasing seems to be detected by the NDVI ${ }_{b}$.

The result of the comparison between the $\mathrm{NDVI}_{b}$ at noon (the same as the previous figure) and the crop coefficient $\mathrm{K}_{\mathrm{c}}$ is shown in Figure 8, also in this case the measurements of 2007 and 2008 are put together. Here the $K_{c}$ seems to be much more related to the $\mathrm{NDVI}_{\mathrm{b}}$, in fact, the regression between these two variable gives a significant linear relationship, as clearly shown by the Figure $9\left(r^{2}=0.60, \alpha=0.05\right)$.

An analysis on relationships between NDVI and microclimate was performed. In particular,

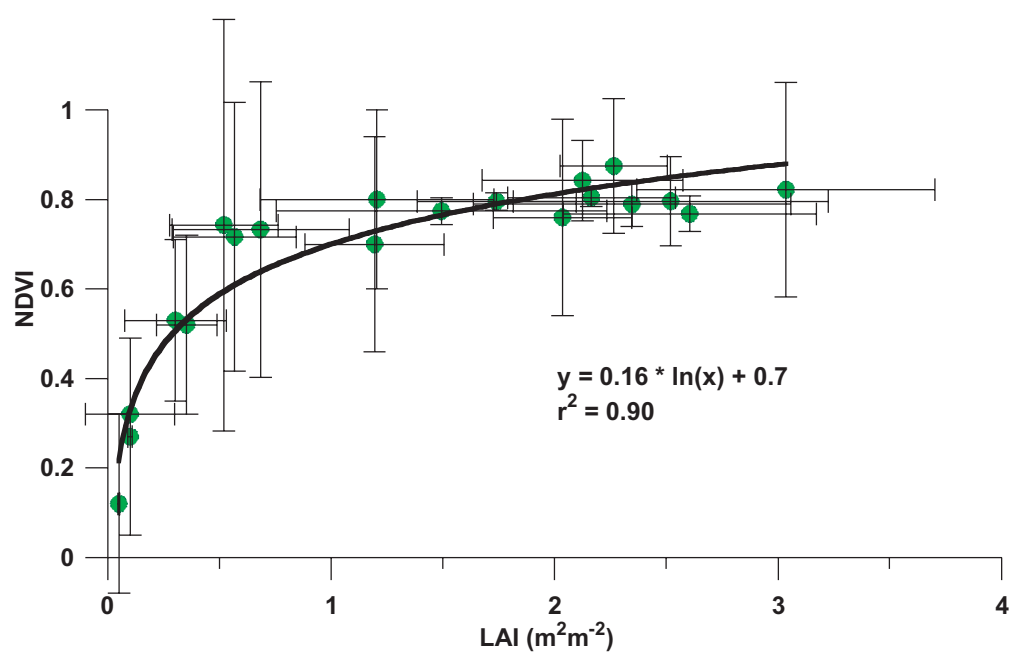

Figure 6. NDVI-LAI relationship. Only the NDVIs (NDVI ${ }_{1}, \mathrm{NDVI}_{2}$, $\mathrm{NDVI}_{\mathrm{b}}$ ) values at noon during the day of LAI measurements are shown. The vertical bars are the standard deviation of NDVI at noon, while the horizontal bars are the standard deviation of LAI measured inside the field. 

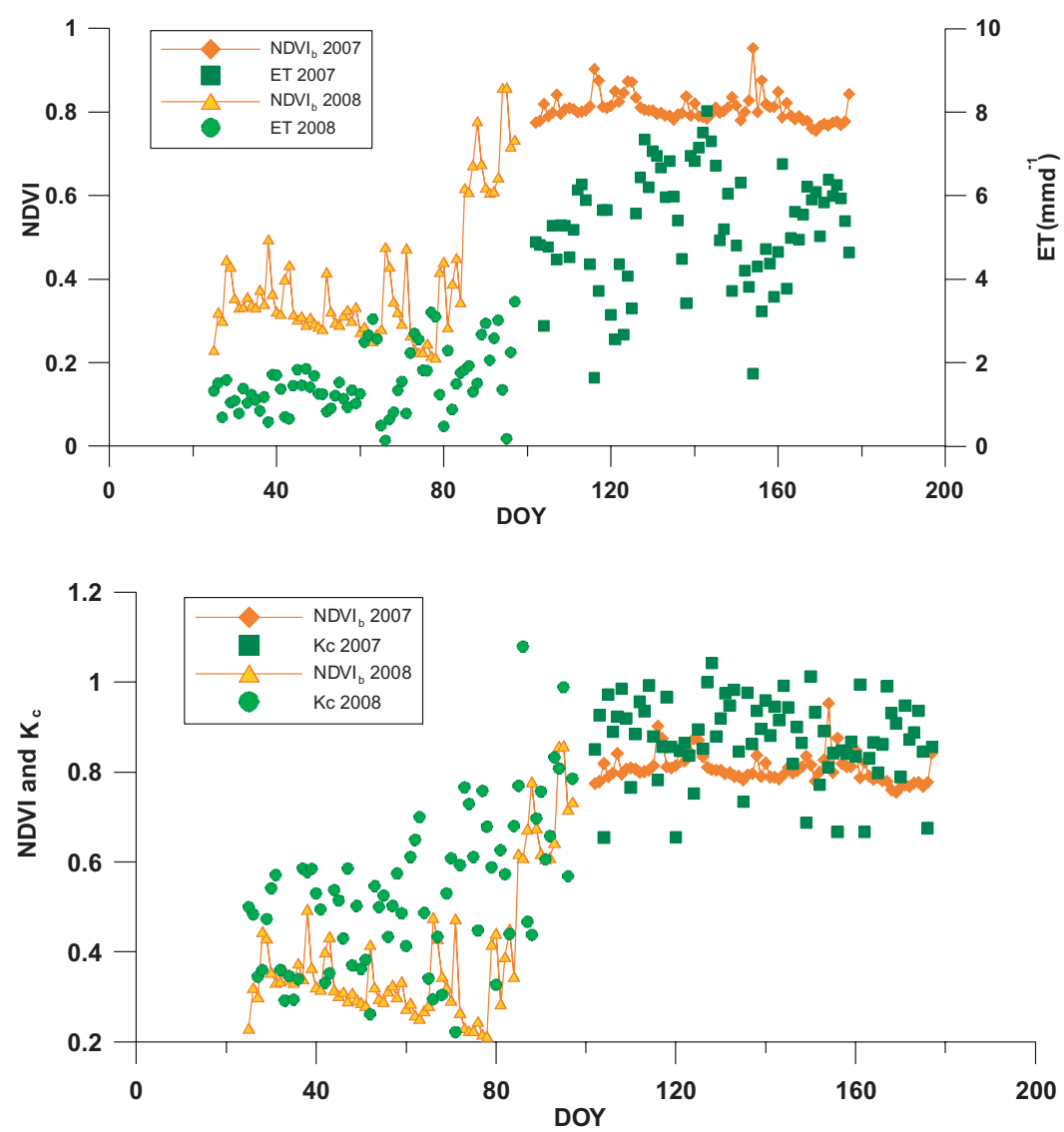

Figure 7. Seasonal course of daily actual evapotranspiration (ET) and $\mathrm{NDVI}_{\mathrm{b}}$ at noon (years 2007 and 2008).
Figure 8. Seasonal course of $\mathrm{K}_{\mathrm{c}}$ and $\mathrm{NDVI}_{\mathrm{b}}$ at noon (years 2007 and 2008). a dependence on air temperature $\left(\mathrm{T}_{\text {air }}\right)$ was investigated, considering also a possible time lag between variation in temperature and NDVI. By using the daily NDVI measured at noon and the mean daily $\mathrm{T}_{\text {air }}$, the cross correlation analy-

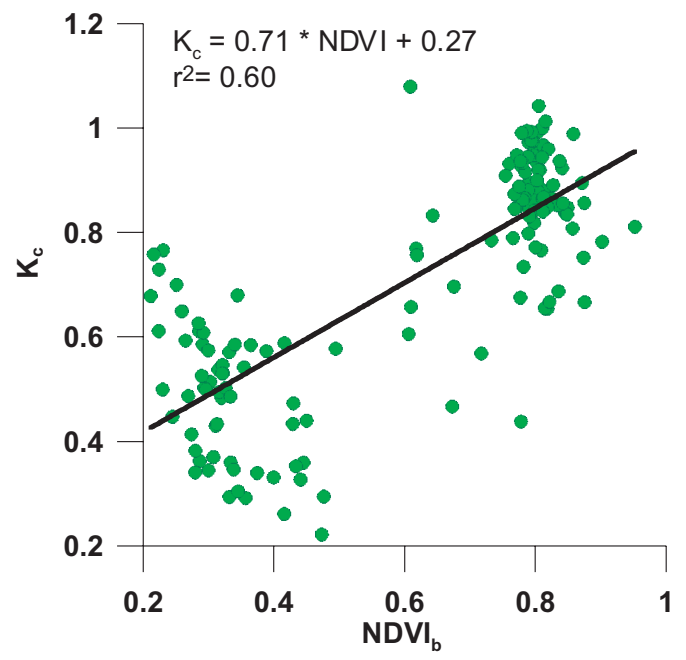

Figure 9. Scatter plot between $\mathrm{K}_{\mathrm{c}}$ and $\mathrm{NDVI}_{\mathrm{b}}$ for the seasons 2007 and 2008. sis between these two variables demonstrated that there was no correlation between them, also shifting one respect the other for many days. Only a direct effect of rain on failure of NDVI measurements was observed, while no relationship with net radiation was found.

\section{Conclusions}

Three techniques to calculate the ground-NDVI have been evaluated in this work, for sugar beet in all its phenological phases. The first one, $\mathrm{NDVI}_{1}$, is based on hand made reflectance measurements, the second one, $\mathrm{NDVI}_{2}$ on automatically reflectance measurements and the third one, the broadband NDVI , on PAR and global radiation measurements. The $\mathrm{NDVI}_{1}$ is difficult to be used in routine because it needs many hand made measurements inside the vegetation in order to take into account the spatial variability of the vegetation structure (LAI, height, soil covering). $\mathrm{NDVI}_{2}$ and $\mathrm{NDVI}_{\mathrm{b}}$ give the same 
values, but the last one is affected by lower variability with respect the first one. Furthermore, $\mathrm{NDVI}_{\mathrm{b}}$ can be determined using standard commercial solar sensors, usually found in agrometeorological stations, thus it is preferable for routinely acquired observations.

The NDVI satellite-derived and the NDVI ground-based are not directly comparable due to the difference in atmospheric influence. However, the relationship between LAI and NDVI by ground-based measurements shows a pattern comparable to the LAI vs satellite-derived NDVI. Moreover, the ground-based LAI vs NDVI relationship could be very useful to couple modelling and remote sensing approaches through forcing and assimilation procedure, also when satellite data are not available. Nevertheless, due to saturation, the use of NDVI for estimation of LAI is in poor or weak accuracy for well developed soil covering crops.

A well established relation has been found between NDVI and crop coefficient $\mathrm{K}_{\mathrm{c}}$ experimentally determined by the ratio between actual and reference measured or modelled evapotranspirations. While the relation between NDVI and crop actual evapotranspiration is very weak and not usable for practical purposes.

The absence of an evident relationship between the microclimate and the NDVI needs to be further investigated in order to be sure that it is not due to instrumental troubles. Longer datasets are needed to be sure that our results are not completely in contrast with the relation between air temperature and $\mathrm{NDVI}_{\mathrm{b}}$ found by Wang et al. (2004) on a forest.

The development of more sophisticated sensors and the refinement of image analysis techniques should overcome the time resolution limitation of satellite data. Recently, the new satellite constellation (4 satellites) of the German society 'RapidEye' is acquiring multispectral remote sensing images for agricultural applications (www.rapideye.de). They provide low cost images, with a spatial resolution of $5 \mathrm{~m}$ and an high time resolution, with the peculiarity to collect data in the "red-edge" spectral band which is more sensitive to chlorophyll changes. This new technology allows the development of new and more accurate vegetation index. In this optics, the ground data are fundamental information to calibrate and validate the remote sensing indices.

\section{Acknowledgment}

This work is supported by Italian Ministry of Agriculture, Food and Forestry Policies under contract n. 209/7303/05 (AQUATER Project). We wish to express thanks to our colleague Dr. Sergio Ruggieri for supplying the topographic maps of the experimental fields.

\section{References}

Allen R.G., Pereira L.S., Raes D., Smith M. 1998. Crop evapotranspiration: guidelines fro computing crop water requirements. FAO Irrigation and Drainage Paper 56, Rome, 300 pp.

Azzali S., Menenti M. 1999. Mapping isogrowth zones on continental scale using temporal Fourier analysis of AVHRR-NDVI data. Int. J. Appl. Earth Obs. Geoinf, 1, 1:9-20.

Bandyopadhyay P.K., Mallick S. 2003. Actual evapotranspiration and crop coefficients of wheat (Triticum aestivum) under vaying moisture levels of humid tropical canal command area. Agric. Wat. Manage., 59:33-47.

Bajwa S.G., Vories E.D. 2006. Spectral response of cotton canopy to water stress. ASAE Annual meeting, paper no. 061064.

Baret F., Guyot G., Major D.J. 1989. Crop biomass evaluation using radiometric measurements. Photogrammetria, 43:241-256.

Brown J.F., Loveland T.R., Merchand J.W., Reed B.C., Ohlen D.O. 1993. Using multisource data in global land-cover characterization: concepts, requirements and methods. Phot. Eng. Rem. Sens., 59:977-987.

Café B., Pessanha L., Bugalho L., Tavares R. 2006. Success stories: application of remote sensing technologies to irrigation advisory services in the Portuguese case study of DEMETER. In: D'Urso G., Osann Jochum M.A., Moreno J. (eds.): Earth Observation for vegetation monitoring and water management, AIP Conference Proceedings, Naples, 2005, 9-10 Nov., published by American Inst. Physics, ISBN -73540346-5/06; 852:43-50.

Choudhury B.J., Ahmed N.U., Idso S.B., Reginato R.J., Daughtry C.S.T. 1994. Relations between evaporation coefficients and vegetation indices studied by model simulations. Rem. Sens. Env., 50:1-17.

Duchemin B., Hadria R., Erraki S., Boulet G., Maisongrande P., Chebouni A., Escafadal R., Ezzahar J., Hoedjes J.C.B., Kharrou M.H., Khabba S., Mougenot B., Olioso A., Rodriguez J.-C., Simonneaux V. 2006. Monitoring wheat phenology and irrigation in Central Morocco: on the use of relationships between evapotranspiration, crop coefficients, leaf area index and remotely-sensed vegetation indices. Agr. Wat. Manage., 79:1-27.

D’Urso G., Calera Belmonte A. 2006. Operative approaches to determine crop water requirements from Earth Observation data: methodologies and applica- 
tions. In: D’Urso G., Osann Jochum M.A., Moreno J. (eds.): Earth Observation for vegetation monitoring and water management, AIP Conference Proceedings, Naples, 2005, 9-10 Nov., published by American Inst. Physics, ISBN -7354-0346-5/06; 852:14-25.

Ferrara R.M., Introna M., Martinelli N., Rana G. 2008. WUE estimation by using direct and indirect modelling of water losses of sugar beet cropped in a semiarid environment. Proceedings of International Conference: "Irrigation in Mediterranean Agriculture: challenge and innovation for the next decades", Naples (IT), 17-18/06/2008. Options Méditerranèennes, series A: Mediterranean Seminars, 84:143-150.

Garatuza-Payan J., Watts C.J. 2005. The use of remote sensing for estimating ET of irrigated wheat and cotton in Northwest Mexico. J. Irr. Drain. Sys., 9, 3-4:301320.

Goward S.N., Huemmeric K.F. 1992. Vegetation canopy PAR absorbance and the normalized difference vegetation index: am assessment using the SAIL model. Rem. Sens. Env., 39:119-140.

Gonzàlez-Dugo M.P., Mateos L. 2006. Spectral vegetation indices fro estimating cotton and sugarbeet evapotranspiration. In: D’Urso G., Osann Jochum M.A., Moreno J. (eds.): Earth Observation for vegetation monitoring and water management, AIP Conference Proceedings, Naples, 2005, 9-10 Nov., published by American Inst. Physics, ISBN -7354-0346-5/06; 852:115-123.

Huemmerich K.F., Black T.A., Jarvis P.G., McCaughey J.H., Halls F.G. 1999. High temporal resolution NDVI phenology from micrometeorological radiation sensors. J. Geop. Res., 104(D22): 27935-27944.

Huete A., Justice C., van Leeuwen W. 1999. MODIS vegetation index (MOD13), algorithm theoretical basis document (ver. 3).

Kaimal J.C., Finnigan J.J. 1994. Atmospheric boundary layer flows: their structure and measurements. Oxford University Press, Oxford.

Katerji N., Rana G. 2008. Crop evapotranspiration measurements and estimation in the Mediterranean region. INRA - CRA, ISBN 978-8-89015-241-2, Bari, Italy.

Katerji N., Rana G. 2006. Modelling evapotranspiration of six irrigated crops under Mediterranean climate conditions. Agric. For. Meteorol., 138, 1-4:142-155.

Katerji N., Perrier A. 1983. Modelisation de l'evapotranspiration reelle d'une parcelle de luzerne: role d'un coefficient culturale. Revue Agron., 3, 6:513-521.

Osann Jochum M.A., Calera A. and all DEMETER partners 2006. Operational space-assisted irrigation advisory services: overview of and lessons learned from the project DEMETER. In: D'Urso G., Osann Jochum M.A., Moreno J. (eds.): Earth Observation for vegetation monitoring and water management, AIP Conference Proceedings, Naples, 2005, 9-10 Nov., published by American Inst. Physics, ISBN -73540346-5/06; 852:3-13.

Perrier A. 1975a. Etude physique de l'évapotranspiration dans les conditions naturelles. I. Evaporation et bilan d'énergie des surfaces naturelles. Ann. Agron., 26:1-18.

Perrier A. 1975b. Etude physique de l'évapotranspiration dans les conditions naturelles. III. Evapotranspiration réelle et potentielle des couverts végétaux. Ann. Agron., 26:229-243.

Prince S.D. 1991. A model of regional primary production for use with coarse solution satellite data. Int. J. Rem. Sens., 12:1313-1330.

Rana G., Katerji N., Mastrorilli M., El maujabber M. 1994. Evapotranspiration and canopy resistance of grass in a Mediterranean region. Theor. Appl. Climatol., 50, 1-2:61-71.

Ray S.S., Dadhwal V.K. 2001. Estimation of crop evapotranspiration of irrigation command area using remote sensing and GIS. Agric. Wat. Manage., 49:239-249.

Richardson A.J., Wiegand C.L., Wanjura D.F., Dusek D., Steiner J.L. 1992. Multisite analyses of spectral biophysical data for sorghum. Remote Sens. Environ., 41:71-82.

Rouse J.W., Haas R.H., Schell J.A., Deering D.W., Harlam J.C. 1974. Monitoring the vernal advancement and retrogradation of natural vegetation. NASA/GSFC, Type III, Final Report, Greenbelt, MD, 1-371.

Samani Z., Bleiweiss M., Schnugge T., Skaggs R. 2006. Monitoring water use in the Rio Grande Valley using remotely sensed data. In: D'Urso G., Osann Jochum M.A., Moreno J. (eds.): Earth Observation for vegetation monitoring and water management, AIP Conference Proceedings, Naples, 2005, 9-10 Nov., published by American Inst. Physics, ISBN -73540346-5/06; 852:93-98.

Sellers P.J., Tucker C.J., Collatz G.J., Los S.O., Justice C.O., Dazlich D.A. 1994. A global 1 by 1 NDVI data set for climate studies: Part 2. The generation of global fields of terrestrial biophysical parameters from NDVI. Int. J. Rem. Sens, 15:3519-3545.

Townshend J.R.G., Justice C.O., Skole D. 1994. The 1 km resolution global data set: needs of the International Geosphere Biosphere Programme. Int. J. Rem. Sens., 15:3417-3441.

Vuolo F., De Michele C., Lazzaro U. 2006. Success stories: analysis and evaluation of the Italian case-study of DEMETER in the Destra Sele Plain. In: D'Urso G., Osann Jochum M.A., Moreno J. (eds.): Earth Observation for vegetation monitoring and water management, AIP Conference Proceedings, Naples, 2005, 9-10 Nov., published by American Inst. Physics, ISBN -7354-0346-5/06; 852:33-42.

Wang Q., Tenhunen J., Quoc Dinh N., Richstein M., Vesala T., Keronen P. 2004. Similarities in ground- and satellite-based NDVI time series and their relationship to physiological activity of a Scots pine forest in Finland. Rem. Sens. Env., 93:225-237.

Wiegand C.L., Richardson A.J. 1990. Use of spectral vegetation indices to infer leaf area index, evapotranspiration and yield: II. Results. Agron. J., 86:630-636. 